\title{
ICBP90 belongs to a new family of proteins with an expression that is deregulated in cancer cells
}

\author{
M Mousli, ${ }^{1,5}$, R Hopfner ${ }^{1,2,5}$, A-Q Abbady', D Monté ${ }^{3}$, M Jeanblanc', P Oudet ${ }^{2}$, B Louis ${ }^{4}$ and C Bronner ${ }^{*, 1}$ \\ 'Inserm U392, Faculté de Pharmacie, 74 route du Rhin, B.P. 60024, 6740I IIIkirch Cedex, France, ${ }^{2}$ IGBMC, CNRS UMR 7I 04, Inserm UI 84, B.P. I63, \\ 67404 IIIKirch, Cedex, France, ${ }^{3}$ Institut de Biologie de Lille, UMR 81 I 7 CNRS/Institut Pasteur de Lille, I rue Calmette, 59021 Lille Cedex, France, ${ }^{4}$ Centre \\ de Pathologie, 18 rue Kempf, 67000 Strasbourg, France
}

ICBP90 (Inverted CCAAT box Binding Protein of $90 \mathrm{kDa}$ ) is a recently identified nuclear protein that binds to one of the inverted CCAAT boxes of the topoisomerase Il $\alpha$ (Topoll $\alpha$ ) gene promoter. Here, we show that ICBP90 shares structural homology with several other proteins, including Np95, the human and mouse NIRF, suggesting the emergence of a new family of nuclear proteins. Towards elucidating the functions of this family, we analysed the expression of ICBP90 in various cancer or noncancer cell lines and in normal or breast carcinoma tissues. We found that cancer cell lines express higher levels of ICBP90 and Topoll $\alpha$ than noncancer cell lines. By using cell-cycle phase-blocking drugs, we show that in primary cultured human lung fibroblasts, ICBP90 expression peaks at late GI and during G2/M phases. In contrast, cancer cell lines such as HeLa, Jurkat and A549 show constant ICBP90 expression throughout the entire cell cycle. The effect of overexpression of E2F-I is more efficient on ICBP90 and Topoll $\alpha$ expression in noncancer cells (IMR90, WI38) than in cancer cells (U2OS, SaOs). Together, these results show that ICBP90 expression is altered in cancer cell lines and is upregulated by E2F-I overexpression with an efficiency depending on the cancer status of the cell line. British Journal of Cancer (2003) 89, 120-127. doi:I0.1038/sj.bjc.6601068 www.bjcancer.com (C) 2003 Cancer Research UK

Keywords: ICBP90; topoisomerase Il $\alpha$; cancer; cell cycle; E2F; retinoblastoma protein

DNA-topoisomerase II $\alpha$ (TopoII $\alpha$ ) is the primary target of several anticancer drugs currently used in cancer treatments (reviewed in Wang, 1996; Withoff et al, 1996). TopoII $\alpha$ expression correlates with drug sensitivity. For instance, enhanced sensitivity to antiTopoII drugs was observed after adenovirus-mediated TopoII $\alpha$ gene transfer in a human breast cancer cell line (Zhou et al, 2001). There is a marked heterogeneity of TopoII $\alpha$ expression within different breast cancers (Sandri et al, 1996), various tissues (Turley et al, 1997; Withoff et al, 1999) and cell lines (Mo et al, 1998), which is responsible for the wide variety of anti-TopoII drug sensitivity. TopoII $\alpha$ expression is linked to cell growth and is cellcycle regulated (reviewed in Isaacs et al, 1998; Nitiss, 1998). E2F-1 has been reported to regulate TopoII $\alpha$ expression and cell chemosensitivity to anti-TopoII $\alpha$ drugs (Hofland et al, 2000; Kalma et al, 2001; Dong et al, 2002). However, the TopoII $\alpha$ gene promoter lacks an E2F-consensus binding site considering the first 700 nucleotides from the transcription start site (Hochhauser et al, 1992), suggesting the involvement of an intermediary actor in the TopoII $\alpha$ gene regulation by E2F members.

Using the one hybrid system, we have identified a novel human protein able to bind the inverted CCAAT box 2 (ICB2) of the TopoII $\alpha$ gene promoter and that we named ICBP90 (Inverted CCAAT box Binding Protein of $90 \mathrm{kDa}$ ) (Hopfner et al, 2000). The

\footnotetext{
* Correspondence: Dr C Bronner;

E-mail: Christian.Bronner@pharma.u-strasbg.fr

${ }^{5}$ These authors are equal first authors.

Received I 4 November 2002; revised 27 March 2003; accepted 10 April 2003
}

ICB2 is known to play a crucial role in the TopoII $\alpha$ gene expression regulation (Isaacs et al, 1996; Tolner et al, 2001; reviewed in Bronner et al, 2002). We have also recently shown that transient overexpression of ICBP90 could overcome cell contact inhibition by forcing TopoII $\alpha$ expression in primary cultures of human lung fibroblasts (Hopfner et al, 2002). Interestingly, the promoter of the ICBP90 gene contains an E2F-consensus binding site close to one of the transcription start sites (Hopfner et al, 2001). The E2F-1 is a member of the E2F family that is found to be elevated in cancer cells (Lemass et al, 1998; Suzuki et al, 1999).

Consequently, to further elucidate the role of ICBP90, we hypothesised that ICBP90 may be an intermediary actor in the E2F-induced TopoII $\alpha$ expression, and that its expression may be deregulated in cancer cells $v s$ noncancer cells. For this, we investigated (i) whether ICBP90 shares structural features with other proteins exhibiting known properties; (ii) the expression of ICBP90, TopoII $\alpha$ and pRB in various cell lines; (iii) the effects of E2F-1 overexpression on TopoII $\alpha$ and ICBP90 expression; (iv) the cell-cycle-dependent expression of ICBP90 in normal cells $v s$ cancer cells; and (v) the ICBP90 expression in primary breast carcinoma tissue $v s$ noncancer breast tissue.

\section{MATERIALS AND METHODS}

\section{Materials}

The mouse monoclonal antibody (mAb) directed against ICBP90 (1RC1C-10) was engineered in our laboratory by a standard method (Brou et al, 1993). The anti-TopoII $\alpha$ mAb (Ki-S1), alkaline 
phosphatase-conjugated anti-mouse and alkaline phosphataseconjugated anti-rabbit antibodies were purchased from Roche Diagnostics (Mannheim, Germany). The anti-E2F-1 mAb was obtained from BD Biosciences Clontech (Palo Alto, CA, USA). The rabbit antiactin antibody, aphidicolin, L-mimosine, nocodazole and propidium iodide were obtained from Sigma Chemicals (St Louis, MO, USA) and the mouse anti-pRB (retinoblastoma protein) mAb MAB3186 from Chemicon International (Temecula, CA, USA). Tween ${ }^{\circledR} 20$, nitro blue tetrazolium/5-bromo-4-chloro-3indolyl-phosphate (NBT/BCIP) stock solution and protease inhibitor cocktail were from Roche Diagnostics.

\section{Cell cultures and cell synchronisation}

Human lung fibroblasts in primary culture were prepared and cultured as described elsewhere (Hopfner et al, 2000). The human cell lines A549, Jurkat, MCF7, HeLa, 293, WI-38, IMR-90, U2OS, SaOS and MDA were obtained from the American Type Culture Collection (Manassas, VA, USA) and were grown in DMEM supplemented with $10 \%$ FCS, $2 \mathrm{mM}$ glutamine, $100 \mathrm{U} \mathrm{ml}^{-1}$ penicillin and $50 \mu \mathrm{g} \mathrm{ml}^{-1}$ streptomycin.

To synchronise fibroblasts, HeLa, A549 and Jurkat cells were treated with L-mimosine $\left(100 \mu \mathrm{g} \mathrm{ml}^{-1}\right)$, aphidicolin $\left(1 \mu \mathrm{g} \mathrm{ml}^{-1}\right)$ or nocodazole $\left(50 \mathrm{ng} \mathrm{ml}^{-1}\right)$ for $20 \mathrm{~h}$ to arrest cells in the $\mathrm{G} 1$ phase, the $\mathrm{S}$ phase or in the G2/M phases, respectively (Cheng and Kuchta, 1993; Vasquez et al, 1997; Wang et al, 2000). Cells were released from cell-cycle blocks by washing with phosphate-buffered saline (PBS) at $\mathrm{pH} 7.4$, and fresh medium was added.

\section{Adenoviral infections}

The recombinant adenovirus AdCMV-Flag-E2F1 was obtained by insertion of the human E2F-1 coding sequence into the pAdCMVFlag vector, followed by homologous recombination in Escherichia coli (Blais et al, 2002). The FLAG epitope (MAYKDDDKL) was appended at the N-terminus of the coding sequence of human E2F1 to allow easy detection of transgene expression by Western blot. Details of cloning are available upon request. Viral stocks were produced as previously described (Blais et al, 2002) and viral titres were determined by a plaque assay in 293 cells and defined as $\mathrm{PFU} \mathrm{ml} \mathrm{m}^{-1}$. Cells were then infected by adding virus stocks directly to the culture medium at an input multiplicity ranging between 100 and 300 viral particles per cell. The infected cells were harvested $18 \mathrm{~h}$ later and total proteins were extracted for immunodetection as described (Blais et al, 2002).

\section{Flow cytometry}

Cell suspensions were fixed by incubation for $15 \mathrm{~min}$ on ice with $5 \%$ formaldehyde in PBS, followed by resuspension in $100 \%$ ethanol and storage at $-20^{\circ} \mathrm{C}$ for $16 \mathrm{~h}$. DNA labelling was obtained by incubation for $10 \mathrm{~h}$ at $20^{\circ} \mathrm{C}$ in darkness with $50 \mu \mathrm{g} \mathrm{ml}^{-1}$ of propidium iodide and $50 \mu \mathrm{g} \mathrm{ml}^{-1}$ of RNAse A. Experiments were performed with at least 10000 cells. The propidium iodide fluorescence was quantified with a FACScan flow cytometer and data were analysed with the CellQuest software (Becton Dickinson, Franklin Lakes, NJ, USA).

\section{Western blotting}

Whole cell extract preparations are described elsewhere (Hopfner et al, 2000; Blais et al, 2002). Blots were probed with either the $1 \mathrm{RC1C}-10 \mathrm{mAb}\left(0.5 \mu \mathrm{g} \mathrm{ml}^{-1}\right)$, the Ki-S1 mAb $\left(0.1 \mu \mathrm{g} \mathrm{ml}^{-1}\right)$, the anti-pRB $\left(2 \mu \mathrm{g} \mathrm{ml}^{-1}\right)$, the anti-E2F-1 $\left(4 \mu \mathrm{g} \mathrm{ml}^{-1}\right)$, or the antiactin antibody $\left(0.8 \mu \mathrm{g} \mathrm{ml}^{-1}\right)$. As secondary antibodies, an alkaline phosphatase-conjugated anti-mouse antibody or, for the antiactin antibody, an alkaline phosphatase-conjugated anti-rabbit antibody was used at $200 \mathrm{mU} \mathrm{ml}^{-1}$. Signals were detected with an NBT/BCIP stock solution according to the instructions of the manufacturer. Protein bands were quantified on scanned blots with the NIH Image 1.62 software (National Institutes of Health, Bethesda, MD, USA).

\section{Immunohistochemistry}

Indirect immunoperoxidase staining of ICBP90 in breast tissues was carried out as described elsewhere (Hopfner et al, 2000). Briefly, specimens from noncancer breast tissue, high-grade or low-grade primary breast carcinomas were embedded in paraffin and fixed in $10 \%$ buffered formalin (Sigma). Histologic sections $(3 \mu \mathrm{m})$ were incubated overnight at room temperature with the 1RC1C-10 mAb, and specifically bound antibodies were visualised by a streptavidin-biotin complex (Dako LSAB2 System Kit, DAKO, Carpinteria, CA, USA).

\section{RESULTS}

\section{Identification of a new family of proteins involved in cell-cycle regulation}

The primary structure alignments of eight proteins, that is, ICBP90 (Hopfner et al, 2000), Np95 (Fujimori et al, 1998), NIRF (NP95/ ICBP90 Ring Finger, Mori et al, 2002), Np97 (mouse NIRF, Genbank accession number BAB68317), a human 259-amino-acidlong protein similar to ICBP90 (Genbank accession number XM_066969), two Arabidopsis thaliana proteins 1 and 2 (Genbank accession numbers AAG29238 and NP_176778, respectively) and an Oryza sativa protein (Genbank accession number AAG03103) are shown in Figure 1. ICBP90 has several structural domains, including a ubiquitin-like domain, a G9a domain and two zincfinger domains. All these features are, so far, only found in Np95 and mouse or human NIRF. The mouse NIRF exhibits $54.8 \%$ of identity with ICBP90 and $52.6 \%$ with the human NIRF. The human and mouse NIRF share $90.3 \%$ identity with each other, whereas the homology between ICBP90 and Np95 only reaches $73.4 \%$. A short human protein of 259 amino acids, which we called SIN259 (for Similar to ICBP90 and NIRF), has also been identified, sharing $61.0 \%$ identity with ICBP90 and $87 \%$ with human NIRF. ICBP90 and NIRF exhibit 21.4 and $18.3 \%$ identity with the $A$. thaliana protein 1, respectively. Also, ICBP90 and NIRF show 19.2 and $17.7 \%$ identity with an $O$. sativa protein, respectively. The $A$. thaliana protein lacks the ubiquitin-like domain as well as the RING finger domain, while the $O$. sativa protein lacks the ubiquitin-like domain as well as the PHD finger domain. It is interesting to mention that the two plant proteins together contain all the structural domains of the three mammalian proteins, except the ubiquitin-like domain that can be considered as dispensable for the activity of these proteins. These similarities would suggest that NIRF and ICBP90 derive from two common ancestral genes, provided that an equivalent of the $O$. sativa protein exists in $A$. thaliana.

A second A. thaliana protein sharing 24.0 and $19 \%$ identity with ICBP90 and NIRF, respectively, possesses a PHD, a RING finger as well as a G9a domain, but not in the order found in ICBP90, therefore questioning its membership to this family.

\section{ICBP90, TopoII $\alpha$ and pRB expression in normal and cancer cell lines}

ICBP90, pRB and TopoII $\alpha$ expression was investigated in MCF-7 (a breast cancer cell line), IMR90 (human embryo lung fibroblasts), WI38 (human embryo lung fibroblasts), U2OS (an osteosarcoma cell line), HeLa (a cervix cancer cell line), 293 (human kidney embryonic cells), MDA468 (a breast cancer cell line) and SaOS cells (an osteosarcoma cell line) (Figure 2A). Cancer cell lines show high levels of ICBP90 and TopoII $\alpha$ 


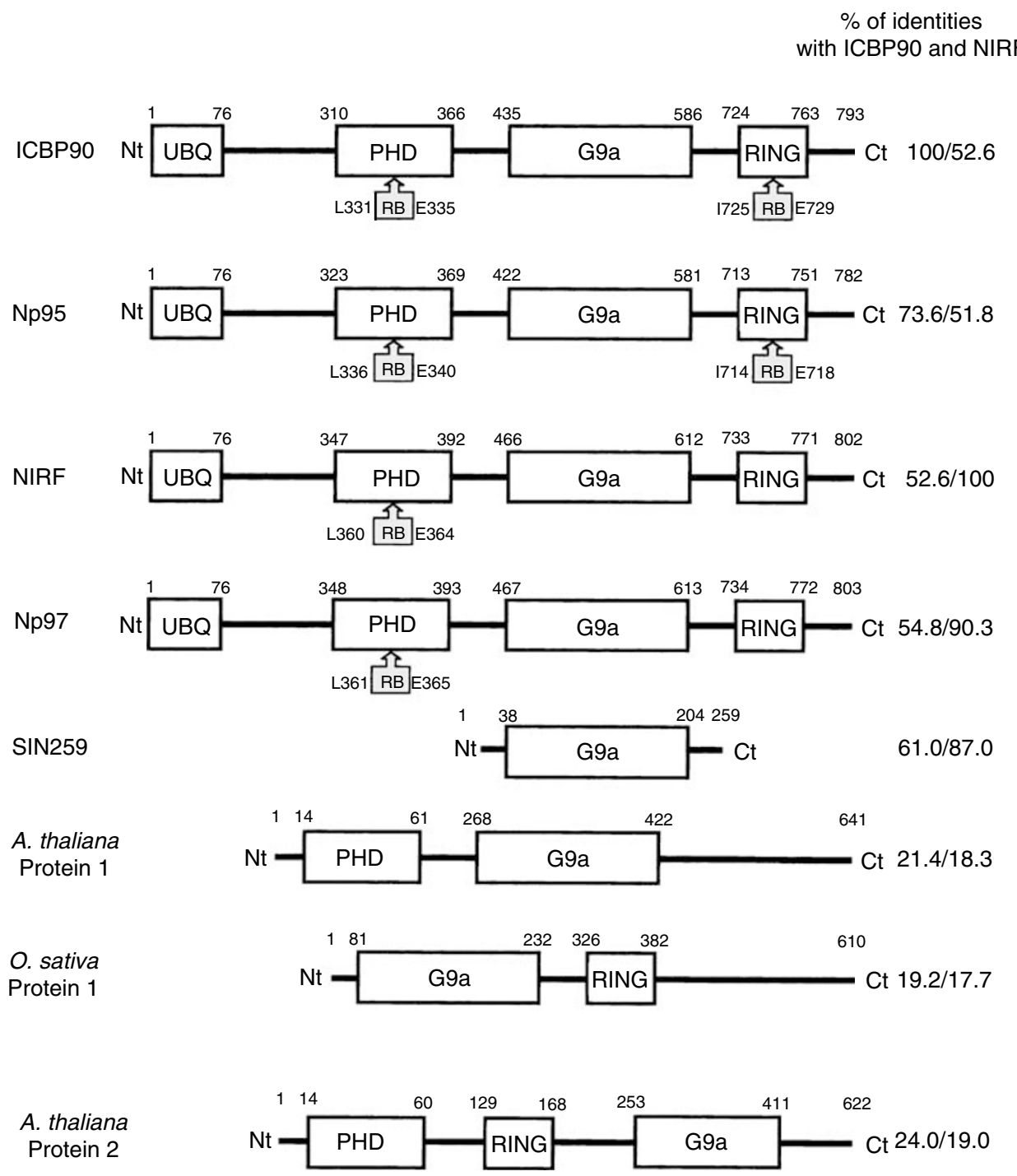

Figure I Structural features of ICBP90, mouse Np95, human Np97 (NIRF), mouse Np97, two A. thaliana proteins and an O. sativa protein. The lengths of the ubiquitin-like domain (UBQ), the PHD finger domain (C3HC4-type), the G9a domain (G9a), the RING finger (C4HC3-type) are delimited by the numbered letters corresponding to the positions of the amino acids. The retinoblastoma protein binding sites (RB) are indicated by the presence of hatched boxes with the positioned amino acids. Information on published data or through Genbank (http://www.ncbi.nlm.nih.gov/) are indicated in the 'Results' section. Values at the C terminal (Ct) of the proteins indicate percentages of identity to ICBP90 and NIRF, respectively, on the length of the concerned proteins. The beginning of the proteins is indicated by Nt (N-terminal part of the proteins). SIN259 means Similar to ICBP90 and NIRF of 259 amino-acids length.

expression. This is the case of MCF-7 (lane 1), U2OS (lane 4), HeLa cells (lane 5), MDA (lane 7) and SaOS (lane 8), and also of 293 cells (lane 6) that are noncancer cells. In contrast, human lung fibroblasts such as IMR90 (lane 2) and WI38 (lane 3) cells exhibit low levels of ICBP90 and TopoII $\alpha$ expression when compared to the previous cancer cell lines. A very good correlation was found between TopoII $\alpha$ and ICBP90 expression (Figure 2B), suggesting that ICBP90 contributes to the elevation of TopoII $\alpha$ expression in cancer cells. U2OS followed by 293 cells and MCF-7 cells are the cell lines that express high levels of pRB. IMR90 and WI38 cells express low levels of pRB. A slight expression of pRB was observed in HeLa cells but it corresponds to the hyperphosphorylated (inactive) form of pRB as the band was slightly higher. MDA and SaOS did not express pRB, but they were chosen in order to see if they expressed the highest levels of TopoII $\alpha$ since in these cell lines pRB cannot exert inhibitory effects on its cellular targets, for example, E2F-1 and putatively ICBP90. Unexpectedly, these cell lines expressed less TopoII $\alpha$ than U2OS or 293 cell lines that showed the highest pRB expressions (Figure 2A).

\section{Effect of E2F-1 overexpression on ICBP90 and TopoII $\alpha$ expression in various cell lines}

Two cancer (SaOs and U2OS) and two noncancer (IMR90 and WI38) cell lines were tested for E2F-1 overexpression experiments (Figure 3). The E2F-1-adenoviral infection of these cell lines led to 7.1-, 12.5- and 10.2-fold increases of E2F-1 expression in SaOS, IMR90 and WI38 cells, respectively. A strong increase of E2F-1 expression in infected U20S cells was observed but could not be calculated, as basal E2F-1 expression was not detectable in our experimental conditions. The order of efficiency of the E2F-1 overexpression on ICBP90 expression was IMR90, WI38, SaOs and U2OS with increases of 990.8, 38.1, 20.9 and 13.3\%, respectively. The order of efficiency of the E2F-1 overexpression on the TopoII $\alpha$ 
A MCF-7 IMR90 WI38 U2OS HeLa 293 MDA SaOs $\begin{array}{llllllll}1 & 2 & 3 & 4 & 5 & 6 & 7 & 8\end{array}$

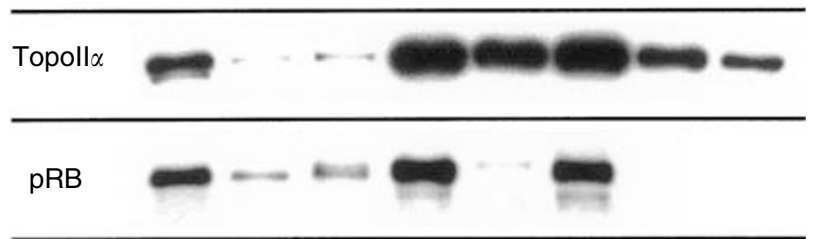

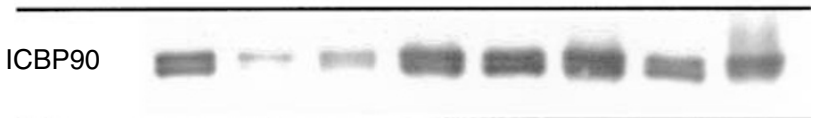

B

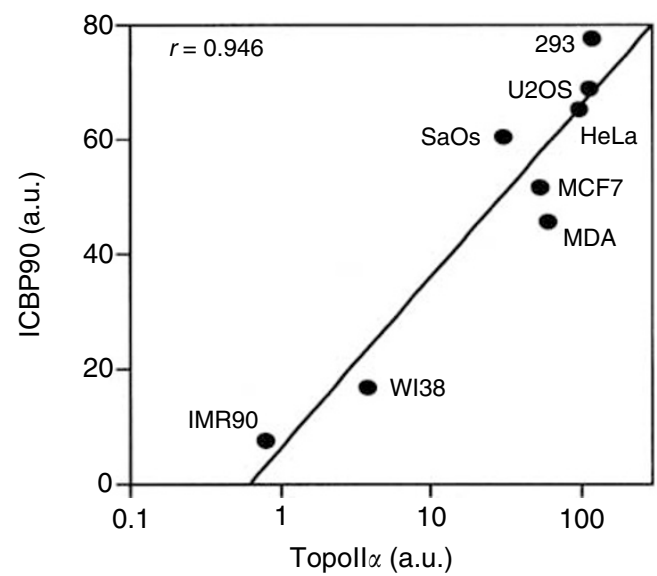

Figure 2 Expression of Topoll $\alpha, p R B$ and ICBP90 in normal and cancer cell lines. (A) Western blot analysis of Topoll $\alpha$, pRB and ICBP90 expression in different cancer cell lines and noncancer cell lines. Lanes I-8 contain whole cell extracts from MCF-7, IMR90, WI38 U2OS, HeLa, 293, MDA468 and $\mathrm{SaOS}$ cells, respectively. For all the cell lines, cells were collected under proliferating conditions, that is, between 60 and $70 \%$ confluence. Labelling with the corresponding monoclonal antibodies is described in 'Materials and Methods'. Data are representative of two separate experiments. (B) Correlation between ICBP90 and Topoll $\alpha$ expression was quantified and expressed as arbitrary units with the $\mathrm{NIH} \mathrm{I.62} \mathrm{image} \mathrm{software} \mathrm{by} \mathrm{scanning}$ the Western blot bands.

expression was IMR90, WI38, U2OS and SaOs with increases of $1445.9,552.5,26.7$ and $13.3 \%$. These results show that overexpression of E2F-1 using adenoviral infection experiments enhances ICBP90 and TopoII $\alpha$ expressions with various efficiencies according to the cell type. Also, these results show that the efficiency of the E2F-1 overexpression on the ICBP90 and TopoII $\alpha$ expression is higher in noncancer cell lines (IMR90 and WI38 cells) than in cancer cell lines (SaOs and U2OS). There is always a good correlation between ICBP90 and TopoII $\alpha$ expression either in noninfected cells (Figure 3B) or in E2F-1 adenoviral infected cells (Figure 3C).

\section{Analysis of ICBP90 expression in noncancer human lung fibroblasts during the cell cycle}

To study the cell cycle of ICBP90 expression in noncancer cells, primary cultured human lung fibroblasts cells were synchronised with reversible cell-cycle-blocking drugs (Figure 4). In unsynchronised fibroblasts, 65,15 and $20 \%$ of the cells were found in G0/G1, $\mathrm{S}$ and G2/M phases, respectively (Figure 4). As a control in the absence of drug, the addition of fresh medium decreased the ICBP90 level from 45.0 arbitrary units (a.u.) (lane 1) to 40.0 a.u.
A

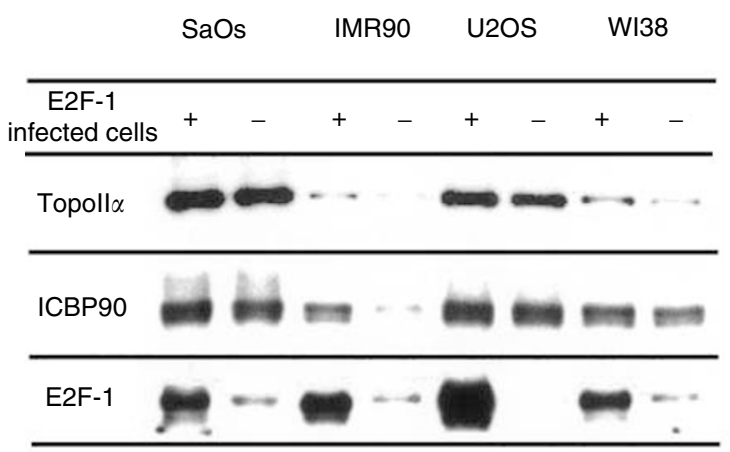

B C
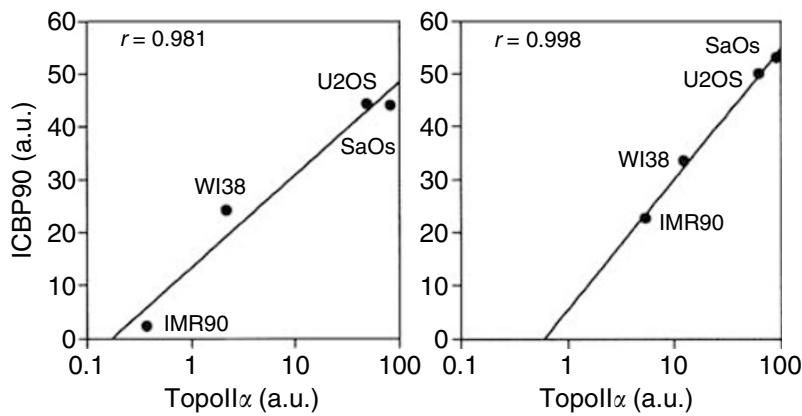

Figure 3 Effects of overexpression of E2F-I on Topoll $\alpha$ and ICBP90 in different cell lines. Infection and Western blot were carried out as described in 'Materials and Methods'. Lanes correspond to $\mathrm{SaOs}(1,2)$, IMR90 $(3,4), \operatorname{U2OS}(5,6)$ and WI38 $(7,8)$ cells transfected with E2F-I or not, respectively, as indicated on the first line. For all cell lines, cells were collected under proliferating conditions, that is, between 60 and $70 \%$ confluence. Data are representative of two separate experiments. (B) Correlation was made with the four cell lines that do not overexpress E2F-I. (C) Correlation was made with the four cell lines that overexpress E2F-I.

(lane 2). In L-mimosine-treated fibroblasts, $88 \%$ of the cells were in G1 phase while $12 \%$ of the cells remained in $S$ and G2/M phases, and ICBP90 expression increased from 45.0 a.u. (lane 1) to 76.7 a.u. (lane 3). After $4 \mathrm{~h}$, ICBP90 levels decreased to 22.2 a.u. (lane 4 ), suggesting that ICBP90 expression decreases as cells enter $\mathrm{S}$ phase. Using the $\mathrm{S}$ phase-blocking drug aphidicolin, the percentage of cells in S phase reached $65 \%$, while $35 \%$ of the cells were still in G1 and no cells remained in the G2/M phases. Arrest by aphidicolin resulted in ICBP90 levels of 37.9 a.u. (lane 5), which increased to 60.8 a.u. $4 \mathrm{~h}$ after drug release (lane 6), indicating an enhancement of ICBP90 as cells leave the $S$ phase. In nocodazole-synchronised fibroblasts, $92 \%$ of the cells were in G2/M phases. The ICBP90 levels reached 62.8 a.u. in G2/M-blocked cells (lane 7), and decreased to 40.8 a.u. $4 \mathrm{~h}$ after drug release, as cells re-enter the G1 phase (lane 8). Together, these results show that ICBP90 levels are maximum in L-mimosine- and nocodazole-treated human lung fibroblasts. Similar results were obtained with human tracheal smooth muscle cells, whereas aphidicolin and nocodazole were without any effect on the ICBP90 expression in HeLa cells (data not shown).

\section{Expression of ICBP90 in lung fibroblasts and HeLa cells synchronised with L-mimosine}

Figure 5 shows the cell-cycle expression of ICBP90 and TopoII $\alpha$ in human lung fibroblasts and HeLa cells. Synchronisation of the human lung fibroblasts at late G1 by L-mimosine conducted to 

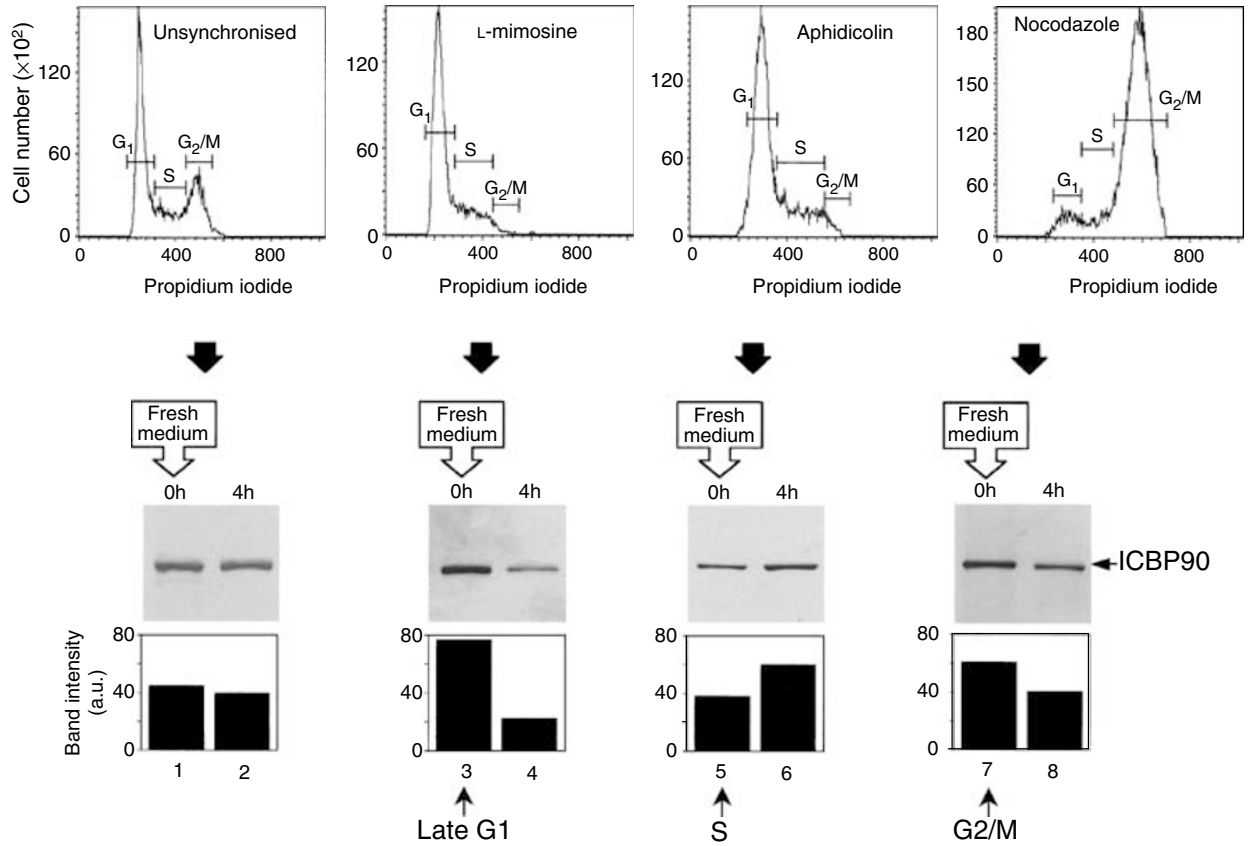

Figure 4 Cell-cycle expression of ICBP90 in human lung fibroblasts. Fibroblasts were synchronised in late GI phase, S phase and G2/M phases with cellcycle-blocking drugs L-mimosine $\left(100 \mu \mathrm{g} \mathrm{ml}^{-1}\right)$, aphidicolin $\left(\mid \mu \mathrm{g} \mathrm{ml}^{-1}\right)$ and nocodazole $\left(50 \mathrm{ng} \mathrm{ml}^{-1}\right)$, respectively. Cell-cycle profiles of synchronised cells were determined by flow cytometry (upper panels). ICBP90 levels were analysed in cell-cycle-blocked fibroblasts (lower panels, lanes I, 3, 5 and 7) and then determined $4 \mathrm{~h}$ after addition of fresh medium without drug (lower panels, lanes 2, 4, 6 and 8 ). Protein bands were quantified on scanned blots with the $\mathrm{NIH}$ Image 1.62 software. Column graphs indicate protein amount for each band in a.u. Data are representative of three independent experiments.

ICBP90 and TopoII $\alpha$ expressions of 78.4 and 53.8 a.u., respectively (lane 1). After $4 \mathrm{~h}$ of drug release, the ICBP90 level decreased to 25.8 a.u., whereas the TopoII $\alpha$ level remained stable at 41.0 a.u. (lane 2). However, after $10 \mathrm{~h}$ of incubation, ICBP90 levels increased to 38.8 a.u. and TopoII $\alpha$ expression reached its highest level of 112.0 a.u., (lane 3). After $12 \mathrm{~h}$ of incubation, a slight increase in ICBP90 and a decrease in TopoII $\alpha$ expression occurred (lane 4). After $24 \mathrm{~h}$, ICBP90 and TopoII $\alpha$ levels decreased to 22.8 and 44.3 a.u., respectively (lane 5). In L-mimosine-synchronised HeLa cells, an ICBP90 level of 82.1 a.u. was observed (lane 6), similar to that observed for fibroblasts (lane 1), and no significant variation was observed after L-mimosine release. Indeed, the ICBP90 protein level was stable at $84.6 \pm 2.1$ a.u. from 4 to $24 \mathrm{~h}$ of incubation (lanes 7 -10). For these late G1-arrested cells, a high TopoII $\alpha$ protein level of 80.2 a.u. was observed (lane 6). The TopoII $\alpha$ level increased progressively after release of L-mimosine from 93, 98, 105 to 115 a.u. after $4,8,12$ and 24 h of incubation, respectively (lanes 7 10). This was not surprising, as TopoII $\alpha$ expression is known to maintain its cell-cycle-dependent regulation in cancer cells, notably in HeLa cells (Isaacs et al, 1998). A similar cell-cycleindependent expression of ICBP90 was obtained with several other cancer cell lines including the A549 cell line and the Jurkat T cell line (data not shown).

\section{Expression of ICBP90 in breast carcinoma tissues $v s$ normal breast tissue}

The expression of ICBP90 was investigated in low-grade or highgrade primary breast carcinomas compared to normal breast tissue (Figure 6). The percentages of ICBP90-labelled nuclei were $<1,5$ and $15 \%$ for normal breast tissue (Figure 6A), low-grade (Figure 6B) and high-grade carcinomas (Figure 6C), respectively. These results show that cells expressing ICBP90 were very low in normal breast tissue, whereas in breast carcinomas the percentage of ICBP90-positive cells appears to follow the grade.

\section{DISCUSSION}

We have recently identified a new protein able to bind, in vitro, the ICB2 element of the human TopoII $\alpha$ gene promoter (Hopfner et al, 2000). Proteins shown in Figure 1 appear to belong to the same family of proteins involved in cell proliferation. The function of these proteins is not yet known, except for ICBP90, which is a putative regulator of the TopoII $\alpha$ gene expression (Hopfner et al, $2000,2002)$. They share several structural domains including two zinc finger domains (one of the PHD finger type and one of the RING finger type) and a G9a domain of unknown function. Interestingly, ICBP90, Np95 and the mouse and human NIRF share the $\mathrm{Rb}$-binding site located in the PHD finger, but that located in the RING finger is present only in ICBP90 and Np95. This suggests that NIRF may have distinguished regulatory mechanism. Nevertheless, with $73.6 \%$ of identity we cannot yet conclude that Np95 is the mouse counterpart of ICBP 90 since the identity between the mouse and human NIRF is $90.3 \%$, a percentage that is usually expected for interspecies homologies between transcription factors. Since the Np95 gene appears to participate in the stability of the genome (Muto et al, 2002), it is not excluded that ICBP90 and/or the aligned proteins exhibit features of tumour suppressor genes. Altogether these proteins may constitute a new family of transcription factors involved in cell proliferation.

ICBP90 peaks at late $\mathrm{G} 1$ and during G2/M phases in human lung fibroblasts. Since the increase in ICBP90 expression is maximum in late $\mathrm{G} 1$, we propose that ICBP90 is the transcription factor participating in the TopoII $\alpha$ gene induction at the G1/S boundary. Such suggestion is consistent with the lack of E2F-binding sites in the TopoIIagene promoter (Hochhauser et al, 1992) known to be important for induction of genes at the G1 to $S$ transition (reviewed in Müller and Helin, 2000). TopoII $\alpha$ expression correlates well with ICBP90 expression after E2F-1 overexpression, suggesting that ICBP90 is the intermediary in the E2F-1-induced TopoII $\alpha$ gene expression. However, we do not exclude other possibilities such as the eviction of an $\mathrm{Rb}$-associated repressor 

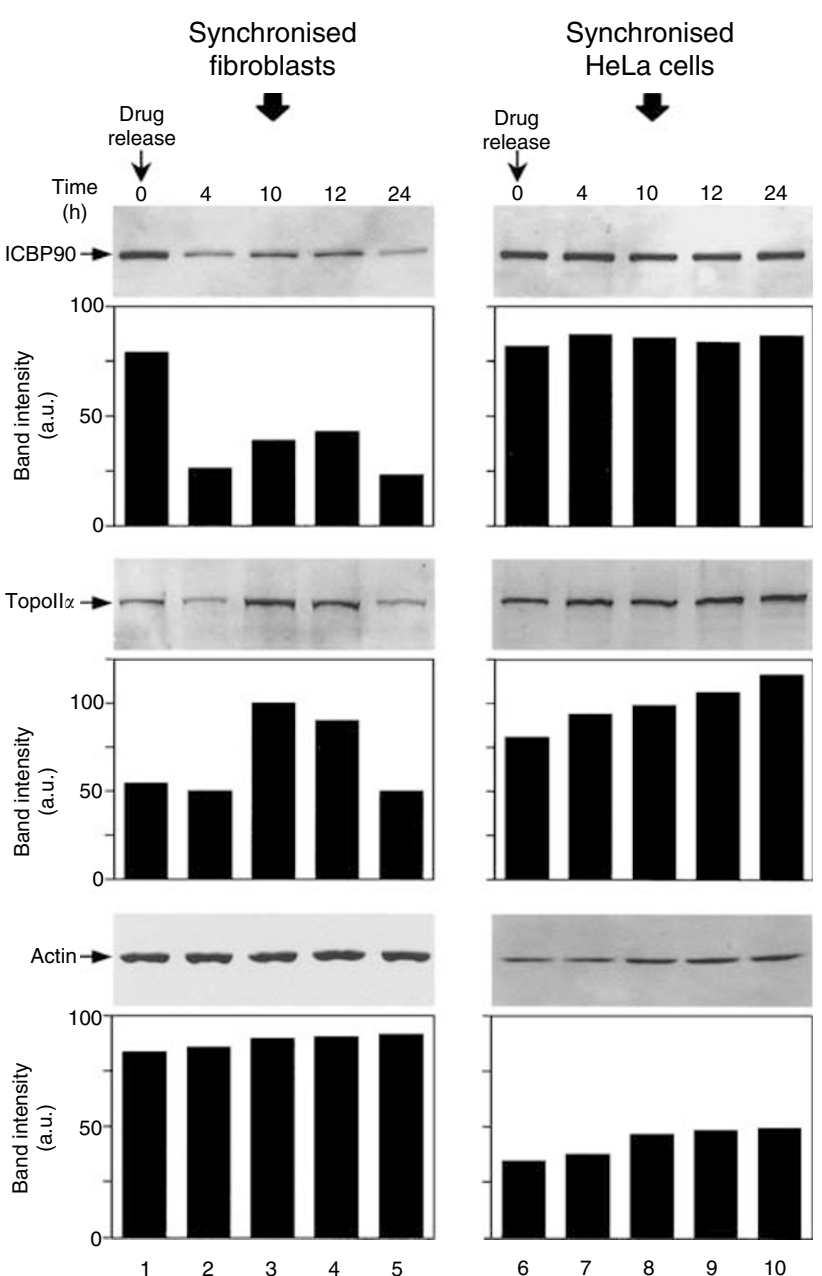

Figure 5 ICBP90 expression is cell-cycle-regulated in noncancer human lung fibroblasts, but not in the HeLa cell line. Lung fibroblasts and HeLa cells were synchronised at late GI with L-mimosine at $100 \mu \mathrm{g} \mathrm{ml}^{-1}$. Cells were washed with PBS to remove L-mimosine (Drug release), then fresh medium was added and the synchronised cells were incubated for $24 \mathrm{~h}$. At indicated times, synchronised fibroblasts (lanes I-5) and synchronised HeLa cells (lanes 6-10) were collected and used to prepare cell lysates that were analysed by Western blot to determine ICBP90, Topoll $\alpha$ and actin levels. Protein bands were analysed on scanned blots with the $\mathrm{NIH}$ Image I.62 software. Column graphs indicate protein amounts in a.u. Data are representative of four separate experiments.

complex from the TopoII $\alpha$ gene promoter by E2F-1. The transition from $\mathrm{Gl}$ to $\mathrm{S}$ phase is regulated by phosphorylation of the retinoblastoma protein ( $\mathrm{pRB}$ ) that is mediated by cyclin-dependent kinases (reviewed in Kaelin, 1999). The hypophosphorylated form of $\mathrm{pRB}$ interacts with transcription factors, for example and by this way counteracts their transcriptional activity. Considering the presence of consensus pRB-binding sites in ICBP90, we expected to find the highest TopoII $\alpha$ expression in pRB-null cells. Unfortunately, this was not the case questioning, at least in these cancer cell lines, whether ICBP90-dependent TopoII $\alpha$ expression is sensitive to $\mathrm{pRB}$ regulation.

Higher expression of ICBP90 was found in cancer cell lines (SaOs, MCF-7, U2OS, HeLa, MDA468) than noncancer cell lines (WI38, IMR90). The cell line 293 (an embryonic kidney cell line) appears to be an exception, but foetal kidney is among the ICBP90 mRNA richest tissues (Hopfner et al, 2000) as is the case for NIRF (Mori et al, 2002). This high expression of ICBP90 correlates with high levels of TopoII $\alpha$, presenting ICBP90 as being involved in the

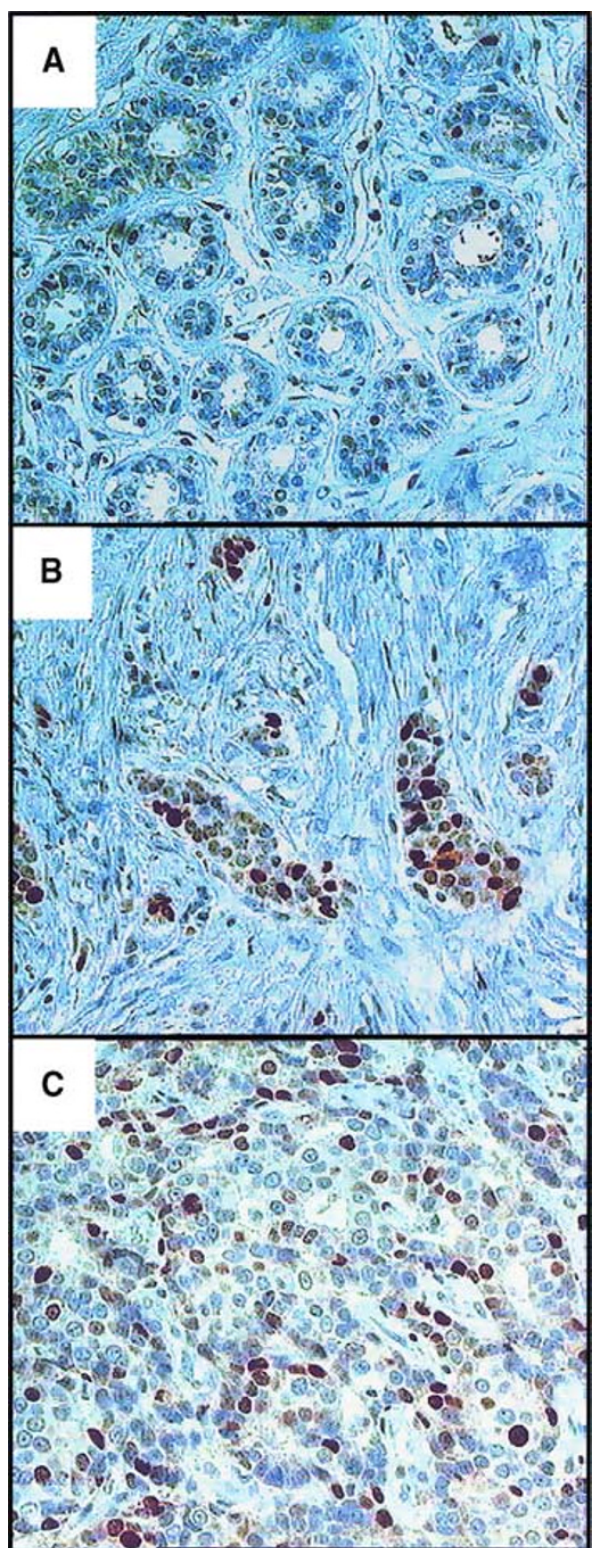

Figure 6 ICBP90 expression in normal breast tissue and breast carcinomas. Immunoperoxidase staining was carried out on histological sections in normal breast tissue $(\mathbf{A})$ and in low-grade $(\mathbf{B})$ or high-grade breast carcinomas $(\mathbf{C})$ with the anti-ICBP90 mAb $\left(0.2 \mu \mathrm{g} \mathrm{ml}^{-1}\right)$. Original magnification: $\times 400$.

overexpression of TopoII $\alpha$ in cancer cells (reviewed in Withoff et al, 1996; Isaacs et al, 1998). This higher expression may come from the lack of downregulation at confluence and/or during certain phases of the cell cycle. Indeed, we have previously shown that ICBP90 is still expressed in HeLa cells at confluence, whereas it is not expressed in confluent human fibroblasts (Hopfner et al, 2000). Furthermore, in the present study, we showed that the ICBP90 cell-cycle-dependent expression disappeared in HeLa, Jurkat cells and A549 cells. Np95 expression was shown to be upregulated in the Sphase and downregulated in G2/M phases in normal mouse $\mathrm{T}$ cells, but this variation was abolished in mouse tumour T cells (Muto et al, 1995). Also, human NIRF was shown to be still expressed in cancer cell lines at confluence but not in normal fibroblasts such as WI38 (Mori et al, 2002). Therefore, we propose that cell-cycle-deregulated expression of the members of 
this family of proteins is a new marker of malignity for cancer cell identification. Interestingly, we found that normal breast tissue was almost negative for ICBP90 staining, whereas a relation seems to take shape between the number of ICBP90-positive cells and the grade.

We found that E2F-1 overexpression increases TopoII $\alpha$ expression and ICBP90 expression, suggesting that this latter is an intermediary candidate in the E2F-1-mediated TopoII $\alpha$ gene regulation (Hofland et al, 2000). The increase is moderate in cancer cells, such as SaOs cells, whereas it is highly efficient in noncancer cells, for example in the IMR90 cell line, probably due to the fact that ICBP90 is already expressed at a high level before E2F-1 overexpression. Therefore, it could explain why the E2F-1 overexpression is less efficient in SaOs cells than other cell lines in terms of sensitisation to anti-TopoII $\alpha$ drugs (Yang et al, 2001; Dong et al, 2002). Since these cells are pRB and p53 null cells, it is likely that the basal expression of E2F-1 is sufficient to induce submaximal ICBP90 and TopoII $\alpha$ expression, which would consequently minimize the effect of an E2F-1 overexpression on the cell sensitivity to anti-TopoII drugs (Yang et al, 2001). Furthermore, we believe that the deregulation of the ICBP90

\section{REFERENCES}

Blais A, Monté D, Pouliot F, Labrie C (2002) Regulation of the human cyclin-dependent kinase inhibitor p18INK4c by the transcription factors E2F1 and Sp1. J Biol Chem 277: 31679-31693

Bronner C, Hopfner R, Mousli M (2002) Transcriptional regulation of the topoisomerase IIalpha gene. Anticancer Res 22: 605-612

Brou C, Chaudhary S, Davidson I, Lutz Y, Wu J, Egly JM, Tora L, Chambon P (1993) Distinct TFIID complexes mediate the effect of different transcriptional activators. EMBO J 12: 489-499

Cheng CH, Kuchta RD (1993) DNA polymerase epsilon: aphidicolin inhibition and the relationship between polymerase and exonuclease activity. Biochemistry 32: $8568-8574$

Dong YB, Yang HL, Elliott MJ, McMasters KM (2002) Adenovirus-mediated E2F-1 gene transfer sensitizes melanoma cells to apoptosis induced by topoisomerase II inhibitors. Cancer Res 62: 1776-1783

Fujimori A, Matsuda Y, Takemoto Y, Hashimoto Y, Kubo E, Araki R, Fukumura R, Mita K, Tatsumi K, Muto M (1998) Cloning and mapping of Np95 gene which encodes a novel nuclear protein associated with cell proliferation. Mamm Genome 9: 1032 - 1035

Hochhauser D, Stanway CA, Harris AL, Hickson ID (1992) Cloning and characterization of the $5^{\prime}$-flanking region of the human topoisomerase II $\alpha$ gene. J Biol Chem 267: $18961-18965$

Hofland K, Petersen BO, Falck J, Helin K, Jensen PB, Sehested M (2000) Differential cytotoxic pathways of topoisomerase I and II anticancer agents after overexpression of the E2F-1/DP-1 transcription factor complex. Clin Cancer Res 6: 1488-1497

Hopfner R, Mousli M, Garnier JM, Redon R, du Manoir S, Chatton B, Ghyselinck N, Oudet P, Bronner C (2001) Genomic structure and chromosomal mapping of the gene coding for ICBP90, a protein involved in the regulation of the topoisomerase II $\alpha$ gene expression. Gene 266: $15-23$

Hopfner R, Mousli M, Jeltsch JM, Voulgaris A, Lutz Y, Marin C, Bellocq JP, Oudet P, Bronner C (2000) ICBP90, a novel human CCAAT binding protein, involved in the regulation of topoisomerase II $\alpha$ expression. Cancer Res 60: $121-128$

Hopfner R, Mousli M, Oudet P, Bronner C (2002) Overexpression of ICBP90, a novel CCAAT-binding protein, overcomes cell contact inhibition by forcing topoisomerase II $\alpha$ expression. Anticancer Res 22: $3165-3170$

Isaacs RJ, Davies SL, Sandri MI, Redwood C, Wells NJ, Hickson ID (1998) Physiological regulation of eukaryotic topoisomerase II. Biochim Biophys Acta 1400: $121-137$

Isaacs RJ, Harris AL, Hickson ID (1996) Regulation of the human topoisomerase IIalpha gene promoter in confluence-arrested cells. J Biol Chem 271: $16741-16747$

Kaelin Jr WG (1999) Functions of the retinoblastoma protein. Bio Essays 21: $950-958$ expression in cancer cells involves E2F considering that high E2F activity has been documented in colon tumours and gastric carcinomas (Lemass et al, 1998; Suzuki et al, 1999), that an E2F binding site exits in the promoter of the ICBP90 gene (Hopfner et al, 2001) and that overexpression of E2F-1 has little effect on ICBP90 expression in cancer cell lines $v s$ noncancer cell lines (present results).

In conclusion, we propose that ICBP90 belongs to a new family of proteins whose role remains to be further characterised and whose deregulated expression is a common feature of cancer cells that can be useful for cancer diagnosis.

\section{ACKNOWLEDGEMENTS}

RH was supported by a fellowship from the Fondation pour la Recherche Médicale and from the Ministère de l'Education Nationale, de la Recherche et de la Technologie. Kawtar Bathami and Eric Mathieu are acknowledged for their technical support. The work was supported by the Comité Départemental du HautRhin de la Ligue Nationale contre le Cancer.

Kalma Y, Marash L, Lamed Y, Ginsberg D (2001) Expression analysis using DNA microarrays demonstrates that E2F-1 up-regulates expression of DNA replication genes including replication protein A2. Oncogene 20: $1379-1387$

Lemass H, Ryan E, Mathuna PM, Crowe J, O'Keane JC (1998) Elevated pRB is associated with elevated E2F-1 but not cyclin D1 or cyclin dependent kinase 4 in the colon carcinomas cell cycle. Gastroenterology (Am. Gastroenterol. Assoc. Abstr.) 114: G2612

Mo YY, Wang Q, Beck WT (1998) Down-regulation of topoisomerase IIalpha in CEM cells selected for merbarone resistance is associated with reduced expression of Sp3. Cancer Res 57: 5004-5008

Mori T, Li Y, Hata H, Ono K, Kochi H (2002) NIRF, a novel RING finger protein, is involved in cell-cycle regulation. Biochem Biophys Res Commun 296: $530-536$

Müller H, Helin K (2000) The E2F transcription factors: key regulators of cell proliferation. Biochim Biophys Acta 1470: M1 - M12

Muto M, Kanari Y, Kubo E, Takabe T, Kurihara T, Fujimori A, Tatsumi K (2002) Targeted disruption of Np95 gene renders murine ES cells hypersensitive to DNA damaging agents and DNA replication blocks. $J$ Biol Chem 277: 34549-34555

Muto M, Utsuyama M, Horiguchi T, Kubo E, Sado T, Hirokawa K (1995) The characterization of the monoclonal antibody Th-10a, specific for a nuclear protein appearing in the $S$ phase of the cell cycle in normal thymocytes and its unregulated expression in lymphoma cell lines. Cell Prolif 28: 645-657

Nitiss JL (1998) Investigating the biological functions of DNA topoisomerases in eukaryotic cells. Biochim Biophys Acta 1400: 63-81

Sandri MI, Hochhauser D, Ayton P, Camplejohn RC, Whitehouse R, Turley H, Gatter K, Hickson ID, Harris AL (1996) Differential expression of the topoisomerase II alpha and beta genes in human breast cancers. $\mathrm{Br} J$ Cancer 73: $1518-1524$

Suzuki T, Yasui W, Yokozaki H, Naka K, Ishikawa T, Tahara E (1999) Expression of the E2F family in human gastrointestinal carcinomas. Int $J$ Cancer 81: $535-538$

Tolner B, Hartley JA, Hochhauser D (2001) Transcriptional regulation of topoisomerase II alpha at confluence and pharmacological modulation of expression by bis-benzimidazole drugs. Mol Pharmacol 59: 699-706

Turley H, Comley M, Houlbrook S, Nozaki N, Kikuchi A, Hickson ID, Gatter K, Harris AL (1997) The distribution and expression of the two isoforms of DNA topoisomerase II in normal and neoplastic human tissues. Br J Cancer 75: $1340-1346$

Vasquez RJ, Howell B, Yvon AM, Wadsworth P, Cassimeris L (1997) Nanomolar concentrations of nocodazole alter microtubule dynamic instability in vivo and in vitro. Mol Biol Cell 8: 973-985

Wang G, Miskimins R, Miskimins WK (2000) Mimosine arrests cells in G1 by enhancing the levels of p27(Kip1). Exp Cell Res 254: 64-71 
Wang JC (1996) DNA topoisomerases. Annu Rev Biochem 65: $635-692$

Withoff S, De Jong S, De Vries EGE, Mulder NH (1996) Human DNA topoisomerase II: biochemistry and role in chemotherapy resistance (review). Anticancer Res 16: 1867-1880

Withoff S, van der Zee AG, de Jong S, Hollema H, Smit EF, Mulder NH, de Vries EG (1999) DNA topoisomerase IIalpha and -beta expression in human ovarian cancer. Br J Cancer 79: 748-753
Yang HL, Dong YB, Elliott MJ, Wong SL, McMasters KM (2001) Additive effect of adenovirus-mediated E2F-1 gene transfer and topoisomerase II inhibitors on apoptosis in human osteosarcoma cells. Cancer Gene Ther 8: $241-251$

Zhou Z, Zwelling LA, Ganapathi R, Kleinerman ES (2001) Enhanced etoposide sensitivity following adenovirus-mediated human topoisomerase IIalpha gene transfer is independent of topoisomerase IIbeta. $\mathrm{Br} J$ cancer 85: $747-751$ 